\title{
Administración de justicia y delitos en el Caribe neogranadino, 1832-1853 ${ }^{1}$
}

\author{
Administração da justiça e crimes no Caribe de Nova Granada, 1832 - \\ 1853 \\ Roicer Alberto Flórez Bolívar ${ }^{2}$ id \\ Universidad de Cartagena, Colombia.
}

Para citaciones: Flórez, R. (2020).

Administración de justicia y delitos en el Caribe neogranadino, 1832-1853. El taller de la Historia, 12(2), 372-399.

Recibido: Junio de 2020

Aprobado: Septiembre de 2020

Autor de correspondencia: Roicer Alberto Flórez Bolívar

rflorezb@unicartagena.edu.co

Editor: Sergio Paolo Solano. Universidad de Cartagena-Colombia.

Tipología IBN Publindex: Artículo de Investigación

Copyright: $\odot$ 2020. Flórez, R. Este es un artículo de acceso abierto, distribuido bajo los términos de la licencia https://creativecommons.org/licenses/bync-sa/4.0/ la cual permite el uso sin restricciones, distribución y reproducción en cualquier medio, siempre y cuando que el original, el autor y la fuente sean acreditados.

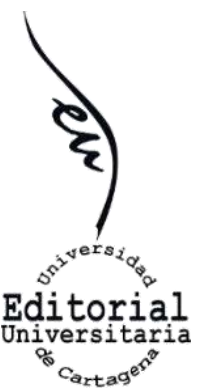

\section{RESUMEN}

Luego del establecimiento de la Nueva Granada como República en 1832, sus autoridades trataron de darle forma a un sistema judicial con cobertura nacional. Este artículo analiza el funcionamiento de este ramo de la administración pública y los delitos más frecuentes en el Caribe neogranadino entre 1832 y 1853 . Argumento que autoridades regionales y locales mediante peticiones y sugiriendo reformas, jugaron un rol central en la formación y fortalecimiento de las instituciones judiciales. El texto, a partir de la revisión de más 1500 edictos, denuncias y sentencias judiciales encontradas en la prensa, evidencia que las mismas estuvieron mayoritariamente relacionadas con delitos contra las personas y las propiedades, al tiempo que es visible una tendencia a no denunciar y juzgar los delitos contra la moral pública. Estos delitos revelan tensiones de clase, raza, género, así como la existencia de una sociedad marcada por la pobreza, los prejuicios raciales y la violencia contra la mujer.

Palabras clave: Nueva Granada; Caribe; provincias; sociedad; estado; justicia; delitos.

\begin{abstract}
After the establishment of New Granada as a Republic in 1832, its authorities tried to shape a judicial system with national coverage. This article analyzes the operation of this branch of public administration and the most frequent crimes in the New Granada Caribbean between 1832 and 1853. I argue that regional and local authorities, through petitions and suggesting reforms, played a central role in the formation and strengthening of judicial institutions. The text, based on the review of more than 1,500 judicial decisions, also shows that they were mostly related to crimes against people and property, while a tendency not to report and judge crimes against public morals is visible. These crimes reveal class, race and gender tensions, as well as the existence of a society marked by poverty, racial prejudice and violence against women.
\end{abstract}

Keywords: New Granada; Caribbean; provinces; society; state; justice; crimes.

\section{RESUMEM}

Após o estabelecimento de Nova Granada como República em 1832, suas autoridades tentaram moldar um sistema judicial com cobertura nacional. Este artigo analisa o funcionamento deste ramo da administração pública e os crimes mais

\footnotetext{
${ }^{1}$ Durante el siglo XIX, la actual Colombia tuvo varios nombres. Entre 1832 y 1858 se llamó República de la Nueva Granada.

${ }^{2}$ Maestría en Historia, Universidad de Cartagena.
} 
frequentes no Caribe de Nova Granada entre 1832 e 1853. Argumento que as autoridades regionais e locais, por meio de petições e sugestões de reformas, desempenharam um papel central na formação e fortalecimento da instituições judiciais. O texto, baseado na revisão de mais de 1.500 édito, denúncias e decisões judiciais veiculadas na imprensa, mostra que eles estiveram principalmente relacionados a crimes contra pessoas e propriedade, enquanto é visível uma tendência de não denunciar e julgar crimes contra a moral pública. Esses crimes revelam tensões de classe, raça e gênero, bem como a existência de uma sociedade marcada pela pobreza, preconceito racial e violência contra a mulher.

Palavras-chave: Nova Granada; Caribe; províncias; sociedade; estado; justiça; crimes.

\section{Presentación}

En 1837, en un reporte sobre la marcha del ramo de justicia, el gobernador de la provincia de Mompox se quejaba del poco impacto de las leyes sobre vagancia en esa jurisdicción. A partir del número de personas procesadas por ese delito, manifestaba que "la sola circunstancia de haber sido juzgados en un año solo tres individuos como vagos, cuando tanto abundan, prueba la ineficacia de la ley de la materia para cortar de raíz este azote que es la verdadera plaga de los Estados"3. Quince años después, su homologo de Santa Marta le señalaba a la Cámara Provincial que, si se llegaran a tener medios más seguros y fáciles de subsistencia, desaparecerían, "sin duda, los dos tercios de procesos de hurto y robo, que es el delito más frecuente y que en su mayor número se origina del malestar y escaseces del pueblo"4.

Los comentarios y quejas de estos gobernadores ilustran uno de los retos del Estado neogranadino durante el siglo XIX: aplicar justicia. Este reto, uno de los aspectos más difícil de alcanzar para un Estado en formación, ha sido investigado por historiadores de América Latina y Europa en las últimas tres décadas, dando como resultado una extensa y variada bibliografía, la cual se ha ocupado de diferentes aspectos como justicia, leyes, pedagogías estatales para controlar a la población; reacciones de los sectores populares a estas medidas de control y otros ${ }^{5}$.

\footnotetext{
${ }^{3}$ Biblioteca Nacional de Colombia (en adelante BNC), "Extracto de la memoria presentada por el gobernador de la provincia de Mompox", Gaceta de la Nueva Granada, Bogotá noviembre 19 de 1837.

${ }^{4} \mathrm{BNC}$, "Informe del gobernador de la provincia de Santa Marta a la Cámara Provincial", Gaceta Oficial de la Nueva Granada, Bogotá, octubre 23 de 1852.

${ }^{5}$ Ante el crecido número de trabajos, señalo algunos libros y balances significativos. Paolo Prodi, Una historia de la justicia. De la pluralidad de fueros al dualismo moderno entre conciencia y derecho, traducido por Luciano Padilla. Buenos Aires: Katz Editores, 2008, p. 447; Darío Barreira y Gabriela Dalla. "El derecho y la justicia entre la historia y la antropología. Breviario de materiales y recursos seleccionados como introducción al tema". Prohistoria, V, 5, (2001): 273-293; Georgina López. "Justicia y criminalidad en el siglo XIX: nuevos enfoques y perspectivas", Signos Históricos N 26, (2011): 8-13; Margarita Garrido. "La justicia y el orden social en Hispanoamérica, siglos XVIII y XIX". Historia Crítica, 26, (2008): 1013; Mirian Galante, "La historiografía reciente de la justicia en México, siglo XIX: perspectivas, temas y aportes". Revista Complutense de Historia de América, 37, (2011): 93-115; Aude Argouse y Hanna Sonkajarvi, "El papel de los procesos judiciales y administrativos en las prácticas de justicia (siglos XVII-XX). Revista Historia y Justicia, 8, (2017): 7-10; Pauline Bilot, "Construyendo un esquema de la administración de justicia: fuentes, métodos, resultados, Chile, siglo XIX". Revista Historia y Justicia, 1, (2013): 1-27; Víctor Brangier y Germán Morong, "Desde la justicia al abordaje historiográfico: los expedientes judiciales-criminales decimonónicos del Archivo Nacional Histórico". Historia Da historiografía, 21, (2016): 96-113; Beatriz Marocco, Prostitutas, jugadores, pobres y vagos en los discursos periodísticos.
} 
Esta reciente literatura, a pesar de su diversidad de temas, se interesa por analizar la justicia y los delitos desde una dimensión socio-histórica. Eso implica que los trabajos referenciados, aunque tienen en cuenta las leyes y las normas, las incorporan no con el fin de describirlas sino para situarlas y localizarlas en sociedad. Esta perspectiva, al tiempo que muestra como la justicia se ajusta y se construye a partir de las realidades locales ${ }^{6}$, utiliza los delitos como una herramienta que permite captar dinámicas económicas, sociales, políticas y establecer pautas y tendencias generales sobre la sociedad y el funcionamiento del Estado ${ }^{7}$.

Aunque la historiografía colombiana no ha sido ajena a estas preocupaciones temáticas al contar actualmente con investigaciones que se han ocupado por entender el funcionamiento de la justicia, las leyes, los delitos y $\operatorname{otros}^{8}$, la historiografía regional del Caribe no ha reflexionado sobre los mismos. Es notable la ausencia de investigaciones sobre justicia y delitos durante el siglo XIX, al existir solo tres trabajos para la segunda mitad de esa centuria. Dos sobre comportamientos delictivos y uno sobre la administración de justicia en el Estado Soberano de Bolívar'. Esta situación contrasta con los avances obtenidos por la historiografía caribeña en las últimas tres décadas ${ }^{10}$. A nuestro juicio, dos razones pueden explicar este escaso interés. La primera es la ausencia de fuentes judiciales en los archivos de la región. No obstante, la digitalización de la información que reposa en algunos archivos y bibliotecas del país ha permitido subsanar esta dificultad. La segunda es que, posiblemente, los historiadores de la región acogieron la idea construida por

\footnotetext{
Porto Alegre, siglo XIX. Barcelona: tesis doctoral, Universidad Autónoma de Barcelona, 2002, p. 288; Silvia Arrom, Para contener al pueblo: el hospicio de pobres de la ciudad de México, 1774-1871. México: Centro de Investigaciones y Estudios Superiores de Antropología Social, 2010, p. 438; Alejandra Araya, "Guerra, intolerancia a la ociosidad y resistencia: los discursos ocultos tras la vagancia, Ciudad de México, 1821-1860”. Boletín Americanista, 52, (2002): 23-55; Yolanda Díaz, "Delitos y delincuentes. Cuba en los finales del siglo XIX e inicios del XX". Pensamiento Americano, 10, 18, (2017): 3245; Martín Rheinheimer, Pobres, mendigos y vagabundos. La supervivencia en la necesidad, 1450-1850. Madrid: Siglo XXI Editores, 2009, p. 237

${ }^{6}$ Juan Vélez, "El establecimiento local de la administración de justicia en Antioquia, 1821-1853. El difícil cumplimiento de una promesa republicana". Anuario Colombiano de Historia Social y de la Cultura, 40, 1, (en adelante ACHSC) (2013): 113-143; Darío Barreira. "La historia de la justicia y las otras historias", en Rodolfo Richard-Jorba y Marta Bonaudo (coords.), Historia regional. Enfoques y articulaciones para complejizar una historia nacional, La Plata: Universidad Nacional 2014, pp. 19-39

${ }^{7}$ Beatriz Patiño, Criminalidad, ley penal y estructura social en la provincia de Antioquia, 1750-1820. Bogotá: Universidad del Rosario, 2013, p. 451.

${ }^{8}$ Francisco Barbosa. Justicia: rupturas y continuidades. El aparato judicial en el proceso de configuración del EstadoNación en Colombia, 1821-1853, (Bogotá: Universidad Javeriana, 2007), 266; Mario Aguilera. "La administración de justicia en el siglo XIX. Pervivencias del sistema español, adaptación de códigos foráneos, penas y castigos", Credencial Historia, Vol. 138 fasc., (2001): 8-11; Germán Colmenares. "El manejo ideológico de la ley en un periodo de transición”, en: Germán Colmenares. Obras completas, (Cali: TM Editores, 1998), 231-264; Beatriz Patiño. Criminalidad, ley penal, 451; Juan Vélez. El establecimiento local 113-143; Juan Carlos Vélez. "Abogados, escríbanos, rábulas y tinterillos. Conflictos por la práctica del derecho en Antioquia, 1821-1843", Estudios Políticos N $^{\circ} 32$, (2008): 13-51; Natalia Botero. "El problema de los excluidos. Las leyes contra la vagancia en Colombia durante las décadas de 1820 a $1840 "$, ACHSC Vol. 39, $\mathrm{N}^{\circ} 2$, (2012): 41-68; Juan Carlos Jurado. Vagos, pobres y mendigos. Contribución a la historia social colombiana, $1750-$ 1850, (Medellín: La Carreta, 2004), 171.

${ }^{9}$ Heriberto Puerta. La administración de justicia en el Estado soberano de Bolívar, 1870-1880, (Cartagena: Cámara Colombiana del Libro, 2011), 349; Ivonne Bravo. Comportamientos Ilícitos y mecanismos de control social en el Bolívar Grande, 1886-1905, (Bogotá: Ministerio de Cultura, 2016), 50; Maico Pitalúa. "Pensar la ciudad desde los márgenes: vagos, ociosos y mal-entretenidos en la provincia de Cartagena a inicios del siglo XX”, Cultura, ciudades y economía en el Caribe: una mirada al litoral. Cartagena, eds. Jorge Elías Caro y Raúl Román. (Barranquilla: Asociación Colombiana de Estudios del Caribe, 2016), 60-72.

${ }^{10}$ Roicer Flórez y Sergio Paolo Solano. "La reciente historiografía social sobre el Caribe colombiano: logros, limitaciones y posibilidades", 20 años de estudios sobre el Caribe colombiano, editado por: Jaime Bonet Morón y Gerson Pérez Valbuena. (Bogotá: Banco de la República, 2020), 39-116.
} 
la historiografía tradicional sobre el ethos del ser caribeño como ajeno a conflictos y violencias ${ }^{11}$.

Teniendo en cuenta lo anterior, este artículo, analizando más de 1500 edictos, denuncias y sentencias encontradas en la prensa, ofrece una mirada inicial a los delitos que con mayor frecuencia se cometieron en las provincias del Caribe neogranadino entre 1832 y 1853 . Pretende responder tres preguntas estrechamente relacionadas: ¿qué rol jugaron los funcionarios judiciales regionales y locales en la configuración del aparato judicial en los inicios de la República neogranadina? ¿cuáles fueron las tendencias delictivas que caracterizaron a las sociedades caribeñas durante el período en estudio? ¿Qué nos revelan tales tendencias sobre las dinámicas sociales en las cuales estaban inmersos los individuos que cometían los delitos? Se argumenta que autoridades provinciales, distritales y cantonales, por su conocimiento sobre el funcionamiento del poder judicial en sus territorios, jugaron un rol central en la expansión de las instituciones encargadas de impartir justicia. En los informes que enviaban a las autoridades nacionales, elevaron peticiones y establecieron recomendaciones encaminadas a garantizar el fortalecimiento de este ramo de la administración pública. En nombre de esa justicia, profirieron sentencias mayoritariamente relacionadas con delitos contra las personas y las propiedades (heridas, homicidios, riñas, maltrato de obra, hurtos y robos), al tiempo que es visible una tendencia a denunciar y/o juzgar poco los delitos cometidos en contra de la moral pública (vagancia, beodez, concubinato). Puestos en contextos, los delitos revelan tensiones de clase, raza, género en la región durante la primera mitad del siglo XIX y, a la vez, permiten mostrar la existencia de una sociedad marcada por la pobreza, los prejuicios raciales, la violencia contra la mujer y la debilidad de la iglesia como institución de control social.

Para el mejor desarrollo de este argumento, divido el artículo en tres partes. En la primera señalo el papel de distritos y provincias en la construcción del Estado, mientras que en la segunda preciso cómo se aplicaba justicia y, en la tercera, muestro que, más allá de las cifras, los delitos ofrecen elementos importantes para comprender dinámicas de clase, raza, género y religión en el Caribe neogranadino.

\section{Distritos, cantones y provincias en la construcción del Estado}

Luego de la desintegración de la Gran Colombia en 1830, proyecto político constituido por los actuales países de Ecuador, Venezuela, Panamá y Colombia, en 1832 la Nueva Granada empezó la lenta tarea de construirse como Estado republicano. Lo primero que hicieron sus autoridades fue adoptar una nueva constitución política en febrero de ese año. Entre las medidas aprobadas estaban la adopción del régimen presidencialista y la organización política y administrativa del país en provincias. Las provincias

${ }^{11}$ Flórez y Solano. La reciente historiografía. 
se dividían en cantones y estos en distritos. El número de provincias, cantones y distritos no fue estable durante el periodo de estudio. Por ejemplo, en 1832 en el Caribe existían cinco provincias: Cartagena, Panamá, Riohacha, Santa Marta y Veraguas. En 1843 fue creada la provincia de Mompox y en 1851 las de Chiriquí, Valledupar y Azuero ${ }^{12}$. La provincia de Mompox se desprendió de Cartagena; la Chiriquí de Veraguas y la de Valledupar de Santa Marta. (Ver mapa I).

Mapa I: Nueva Granada. Provincias del Caribe, 1853.

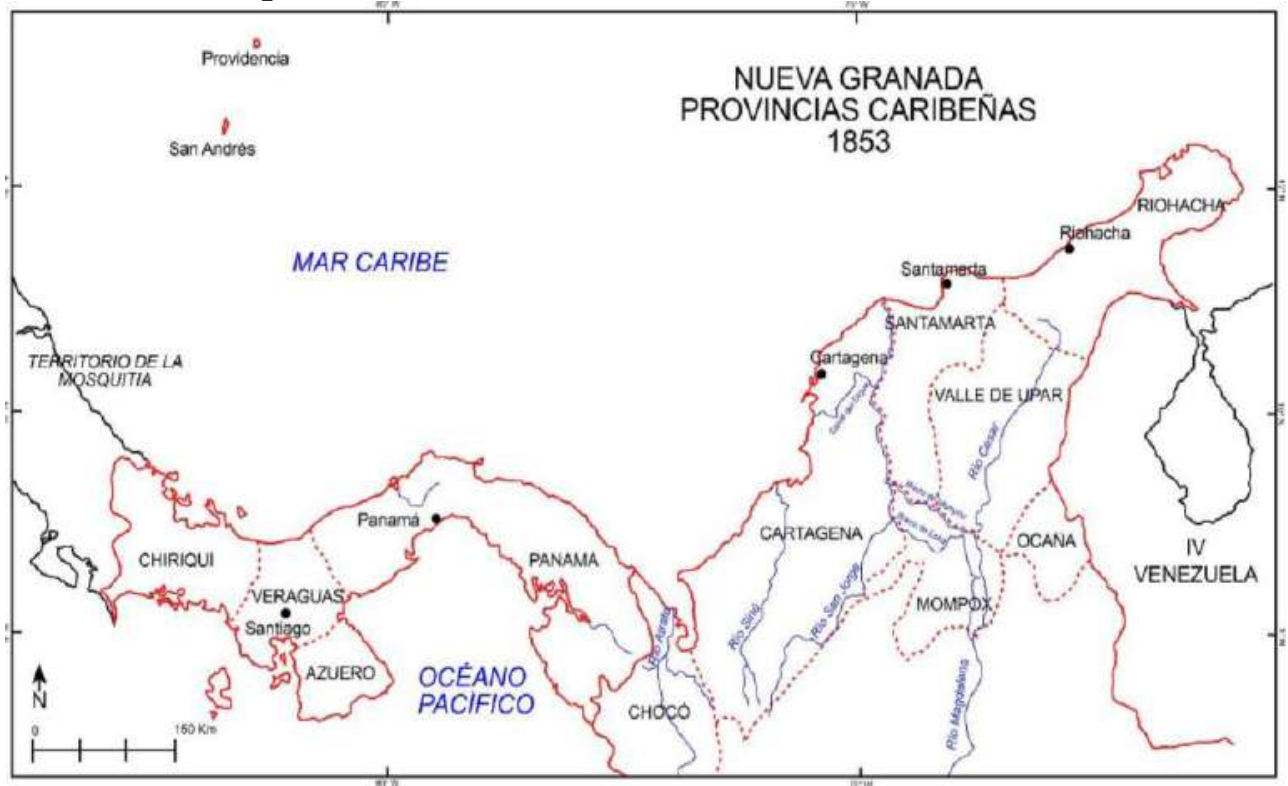

Fuente: Camilo Domínguez, Jeffer Chaparro y Carla Gómez. "Construcción y deconstrucción territorial del Caribe colombiano durante el siglo XIX", Scripta Nova. Vol. $\mathrm{X}, \mathrm{N}^{\circ} 208,(2006), 75-85$.

Estos cambios buscaban mejorar el funcionamiento político y administrativo del Estado, teniendo en cuenta la extensión territorial y los recursos humanos y económicos disponibles en cada una de estas entidades. Las provincias estaban al mando de gobernadores, elegidos por el presidente de la república por un periodo de dos años. Jefes políticos y alcaldes se hallaban al frente de cantones y distritos. Los gobernadores nombraban a los jefes políticos y éstos a los alcaldes. Excepto el de gobernador, los otros dos cargos no eran remunerables. En últimas, gobernadores, jefes políticos y alcaldes representaban a la rama ejecutiva y sobre ellos recaía, entre otras cosas, el mantener el orden público ${ }^{13}$.

Provincias, cantones y distritos también contaban con instituciones legislativas. Las más importantes eran la cámara provincial, los concejos municipales y los concejos comunales. Diputados y concejeros también eran elegidos por dos años. Las cámaras provinciales se reunían anualmente en las

\footnotetext{
${ }^{12}$ Camilo Domínguez, Jeffer Chaparro y Carla Gómez. Construcción y deconstrucción, 75-85.

13 Biblioteca Luís Ángel Arango. "Ley adicional a la orgánica del régimen de las provincias, cantones y distritos parroquiales", Constitucional de Cartagena, (Cartagena) junio 18 de 1836.
} 
capitales de cada provincia. Los concejos municipales residían, además de la capital provincial, en las cabeceras de cantones donde pudieran establecerse y los comunales en los distritos ${ }^{14}$.

La comunicación entre las ramas ejecutiva y legislativa permitía conocer los problemas que afectaban a la población y a la administración pública y, de esta manera, plantear soluciones a los mismos. Los informes de alcaldes, jefes políticos, gobernadores, presidentes de concejos municipales y de cámaras provinciales son herramientas que permiten comprender cómo se va construyendo el Estado republicano desde los niveles distritales y provinciales ${ }^{15}$. Por ley de 1831, anualmente jefes políticos y gobernadores debían visitar cantones y provincias y construir un informe del funcionamiento de estas entidades, el cual era presentado al inicio de las sesiones de los concejos comunales, municipales y cámara provincial ${ }^{16}$. Finalizada las sesiones, los presidentes de estas instituciones le informaban a jefes políticos y gobernadores sobre las decisiones adoptadas para solucionar los problemas identificados. En ese sentido, estos informes detallan, además del cúmulo de lamentaciones sobre los problemas administrativos en los diferentes niveles, las disposiciones tomadas por los representantes de ambas ramas para enfrentar el enorme reto de edificar un Estado que había heredado muchos de los problemas del Estado colonial ${ }^{17}$.

Entre los problemas a resolver en las provincias del Caribe estaban el hacer presencia en un territorio de más de 200.000 kilómetros cuadrados y ejercer control sobre la población, la cual residía un $20 \%$ en los puertos de Cartagena, Santa Marta, Panamá, Barranquilla y Mompox y el $80 \%$ restante vivía dispersa en distritos, aldeas y caseríos que no sobrepasaban los mil habitantes, siendo la pesca, la agricultura y la ganadería sus principales actividades económicas ${ }^{18}$. En los distritos, al ser iletrada la mayor parte de la población, era usual la escasez de personas competentes para ejercer como alcaldes y concejeros municipales, situación que se agravaba porque tales funcionarios, como anoté, no recibían remuneración. No menos grave era la dificultad de cobrar los impuestos por la pobreza de la población. En definitiva, mientras más el Estado descendía de nivel administrativo, su funcionamiento se volvía problemático. En las provincias la marcha oscilaba entre lo bueno y lo regular al contar con recursos para su funcionamiento. A nivel cantonal y distrital, la situación era otra.

\footnotetext{
14 Ley adicional.

${ }^{15}$ Beatriz Rojas. "El municipio libre". Una utopía perdida en el pasado. Los pueblos de Zacatecas, 1786-1835, (México: Instituto Mora, Instituto Cultural de Aguascalientes, Colegio de Bachilleres del Estado de Zacatecas, 2010): 307; Leopoldo Múnera Zea. "Génesis del Estado colombiano: 1810-1831. El proceso de unificación”, Fragmentos de lo Público-Político. Colombia, siglo XIX. Leopoldo Múnera Ruiz y Nathaly Rodríguez Sánchez (editores), (Bogotá: Universidad Nacional de Colombia/ La Carreta Editores, 2008), 11-84.

16 Ley $\quad$ orgánica 19 de $\quad 19$ de $\quad$ mayo $\quad$ de 1831.

bdigital.unal.edu.co > congreso_constitucional_de_1831. Consultado: Junio 20 de 2020.

17 Ley adicional.

18 BLAA, "Designación de electores principales y suplentes de la provincia de Cartagena", Constitucional de Cartagena, (Cartagena) diciembre 20 de 1835.
} 
Conocedores de sus realidades, alcaldes, jefes políticos y gobernadores presentaban proyectos $\mathrm{y}$ recomendaban a concejeros y diputados tomar decisiones sobre finanzas públicas, funcionamiento de la justicia, división territorial, escuelas, policía, hospitales y otros. Un tema recurrente fue la eliminación de distritos y cantones por la carencia de recursos y el poco control sobre el territorio y la población. En 1843, el gobernador de la provincia de Panamá le sugería a la Cámara provincial suprimir el cantón de Darién y anexarlo al de Panamá debido a que su posición geográfica y extensión territorial sobre los océanos Atlántico y Pacífico permitían la práctica del contrabando, afectado aún más las exiguas rentas provinciales ${ }^{19}$. Dos años después, otro gobernador de esa provincia propuso la eliminación de distritos porque existían muchos "donde no hay escuelas, cárceles, curas, alcaldes, ni jueces, pues no hay absolutamente nadie que sepa leer y escribir; no sirviendo aquellos caseríos sino para guarida de los reos prófugos, desertores y contrabandistas" 20 .

El encuentro de los representantes de las ramas legislativas y ejecutivas propiciaba que las Cámaras elevaran peticiones al Congreso de la República destinadas a solucionar dificultades en cada nivel de la administración. Por ejemplo, la carencia de curas en muchos distritos llevó en 1836 a la Cámara provincial de Cartagena solicitar al Congreso extender las excepciones concedidas a Casanare y Pasto, entre las cuales se contemplaba ordenar a los curas sin el grado de teología o los cursos para aprobarlo porque en la provincia un solo cura atendía a dos o a tres iglesias y en su ausencia no había quien lo reemplazara ${ }^{21}$.

Cada petición y decreto de las Cámaras, tras ser aprobadas por el Congreso y el presidente de la República, eran publicadas por la prensa, lo que permite dilucidar las herramientas empleadas por autoridades locales y provinciales para sortear los obstáculos de la administración pública. Muchas veces sucedía que iniciativas provinciales se convertían en política nacional como ocurrió con las Cajas de Ahorros; institución creada en Cartagena en 1843 para enfrentar la crisis económica que vivía la región. La experiencia fue tan significativa que el Congreso aprobó el establecimiento de cajas de ahorros en cada provincia del país ${ }^{22}$.

El conocimiento que gobernadores, jefes políticos, alcaldes, diputados y concejeros tenían sobre el funcionamiento de la administración pública a nivel local y regional, entonces, fue fundamental para que a nivel nacional se tomaran medidas que condujeran al fortalecimiento de la misma. Estos funcionarios, conscientes de que la justicia era uno de los pilares

\footnotetext{
${ }^{19}$ BNC, "Extracto de la memoria presentada a la Cámara provincial por el gobernador de Panamá", Gaceta de la Nueva Granada, Bogotá febrero 26 de 1843.

${ }^{20}$ BNC, "Extracto de la memoria presentada por el gobernador de Panamá a la Cámara provincial", Gaceta de la Nueva Granada, Bogotá febrero 2 de 1845.

${ }^{21}$ BLAA, "Petición de la Cámara provincial", Constitucional de Cartagena, (Cartagena) enero 20 de 1836.

${ }^{22}$ Roicer Flórez y Sergio Paolo Solano. "Los años de las dificultades. La caja de ahorros de la provincia de Cartagena, Nueva Granada, 1843-1853", América Latina en la Historia Económica Vol. 21, º 2, (2014):116-144.
} 
fundaméntalas para garantizar el ideal de igualdad de todos los ciudadanos, también elevarían peticiones tendientes a fortalecer el poder judicial en las provincias entre 1832 y 1853.

\section{Forjando las instituciones judiciales}

Para facilitar la administración de justicia, en medio de las numerosas dificultades que enfrentaba el ramo, en la Constitución de 1832 se establecieron cuatro Distritos Judiciales conformados por tribunales y juzgados, cuyas atribuciones y número de miembros designaba la ley. Estos Distritos fueron el de Cundinamarca con jurisdicción sobre las provincias de Bogotá, Antioquia, Neiva y Mariquita; el de Boyacá (Tunja, Socorro, Pamplona y Casanare); el del Cauca (Popayán, Pasto, Buenaventura y Chocó) y el del Magdalena (Cartagena, Santa Marta, Riohacha, Panamá y Veraguas). En cada Distrito Judicial había un Tribunal de Apelación, que residía en Bogotá, Santa Rosa de Viterbo, Popayán y Cartagena. De igual forma, las provincias contaban con Circuitos Judiciales, los cuales se formaban de dos o más cantones bajo la jurisdicción de un juez de primera instancia, encargado de los negocios comunes, civiles y criminales. El número Circuitos era determinado por la población de las provincias, llevando a que algunas contaran con uno y otras con cinco, siendo este el máximo permitido ${ }^{23}$.

Este diseño institucional judicial se reforzó con la Circular No 30 de 1835 expedida por el presidente Francisco de Paula Santander. La citada circular estableció que alcaldes de cárceles, jueces y magistrados debían informar a alcaldes distritales, jefes políticos y gobernadores sobre reos prófugos, desertores, causas recibidas, notificadas y pendientes para que estos funcionarios las publicaran en los periódicos provinciales. En ese sentido, en periódicos nacionales como la Gaceta de la Nueva Granada y regionales como el Semanario de la Provincia de Cartagena y el Semanario de Santa Marta contaban con una sección denominada "Repertorio Judicial" en el que informaban de los temas señalados anteriormente. ${ }^{24}$

Esta decisión significó un cambio importante con respecto al orden colonial porque ahora, dada la circulación de prensa que sobrevino con la instauración de la República, cualquier ciudadano podía tener conocimiento de las denuncias y sentencias tomadas por jueces y magistrados. Así lo notificó en 1836 Manuel Victoria de la Hoz, juez $2^{\circ}$ de primera instancia del Tercer cantón del distrito de la provincia de Cartagena, quien al referirse a los presos que estaban en la cárcel señaló: "Certifico y juro: que la presente relación está exactamente formada por las noticias que me ha suministrado el escribano con quien actuó en las causas que se expresan y que no existen más presos en la cárcel pública sujetos a mi jurisdicción que los que en ella constan"25.

\footnotetext{
${ }^{23}$ Luz Restrepo. Estructura administrativa de la provincia de Bogotá durante el periodo comprendido entre 1832-1857, (Trabajo de grado para la Maestría en Derecho Administrativo en Universidad del Rosario, 2009), 193; Ley adicional. ${ }^{24}$ BNC, "Repertorio judicial", Gaceta Oficial, Bogotá octubre 15 de 1853.

${ }^{25}$ BLAA, "Tribunal de Justicia del Distrito del Magdalena", Constitucional de Cartagena, (Cartagena) julio 8 de 1836.
} 
Además de lo anterior, para los historiadores interesados en el tema de la justicia y los delitos en el siglo XIX, esta información es útil para analizar comportamientos delictivos y elaborar explicaciones. Adicional a los juicios criminales, los cuales han sido la principal fuente para el estudio de delitos y justicia para el periodo colonial y el siglo $\mathrm{XIX}^{26}$, la prensa decimonónica se convierte en otra herramienta importante a tener en cuenta.

La aprobación del primer Código Penal de la Nueva Granada en 1837, finalmente organizó lo referente a los delitos y sus penas. En ese código, los delitos fueron agrupados en categorías, entre las que estaban las que atentaban contra la constitución; contra la religión; contra la seguridad exterior de la República; contra la tranquilidad y el orden público; contra los funcionarios y empleados públicos; contra los allanamientos de cárceles u otros establecimientos de corrección y castigo; contra la salud pública; contra la fe pública; contra la moral pública; contra la honra, fama y tranquilidad de los particulares; contra la hacienda nacional y contra la libertad de imprenta. ${ }^{27}$.

Cada categoría estaba conformada por un grupo de acciones delictivas. Por ejemplo, los ultrajes, las calumnias, las injurias, los libelos infamatorios, la revelación de los secretos y las amenazas integraban la categoría "contra la honra, fama y tranquilidad de los particulares". Por su parte, la categoría "contra las propiedades" cobijaba a robos, hurtos, estafas, engaños, incendios, piraterías. Los delitos contra las personas se representaban en homicidios, envenenamiento, castramiento, aborto, heridas, maltrato de obra, rapto, estupro, fuerza y violencia y otros. En el caso de los delitos contra la moral pública, estaban las palabras, las pinturas, los escritos y las acciones obscenas; los alcahuetes y los que corrompían jóvenes; los bígamos y los que se casaban clandestinamente; los amancebamientos públicos y escandalosos; los atentados contra la autoridad domestica; los juegos prohibidos y otros. ${ }^{28}$

Citando al historiador Mario Aguilera Peña, en este Código las penas fueron divididas en "corporales" y "no corporales". Las primeras comprendían los trabajos forzados, "la vergüenza pública", la expulsión del territorio nacional y el encierro carcelario que se denominaba como prisión, presidio o reclusión, según el número de años de condena. Las penas no corporales estaban constituidas por la "declaración de infamia", la privación o suspensión de los derechos políticos y civiles, la inhabilitación, suspensión o privación del ejercicio del empleo, profesión o cargo público, la multa, la vigilancia por las autoridades, la fianza de buena conducta, arresto o encierro no superior a cuatro años, y el "apercibimiento" o llamado de atención por un juez de la República. La pena de muerte se ejecutaba mediante el método del "garrote". Con la pena de muerte concurrían los castigos de "vergüenza pública" y la declaratoria de "infamia". Estas dos sanciones se aplicaban simultáneamente

\footnotetext{
${ }^{26}$ Mirian Galante. "La historiografía reciente de la justicia", 93-115; Aude Argouse y Hanna Sonkajarvi. "El papel de los procesos judiciales", 7-10; Pauline Bilot. "Construyendo un esquema de la administración de justicia”, 1-27; Víctor Brangier y Germán Morong. "Los expedientes judiciales-criminales”, 96-113.

${ }^{27}$ Código Penal, p. 87.

${ }^{28}$ Código Penal, p. 124.
} 
en un ritual público que comenzaba sacando al reo de la cárcel con las manos atadas, "descubierta la cabeza, y sobre un jumento", mientras un pregonero indicaba el nombre, la patria, la vecindad, el delito y la pena que iba a sufrir. Luego, el condenado era instalado por dos horas amarrado en el centro de la plaza pública sobre un tablado y con un cartel con las indicaciones ya señaladas. Concluido el tiempo, y sin permitir que el condenado fuera maltratado o injuriado, se le devolvía a la cárcel en las mismas condiciones en que había salido ${ }^{29}$.

En el funcionamiento de todo este aparato de justicia y en la aplicación de las penas contenidas en los códigos era imprescindible que provincias y distritos contaran con funcionarios capacitados, recursos económicos, cuerpos de policía y cárceles seguras para materializar las leyes nacionales. Sin embargo, la mayoría de provincias mostraban falencias en estos y en otros aspectos. Por ejemplo, en 1845 para administrar justicia en las provincias de la Costa se contaba con los Tribunales Superiores del Magdalena, con sede en Cartagena, y el del Istmo, con sede en Panamá. Este último fue creado en 1836 y entró en funcionamiento en 1839 ante la incapacidad del Tribunal del Magdalena de emitir las sentencias en un corto plazo. La norma era el retraso en los juicios, los cuales duraban meses y años, llevando a que muchos enjuiciados no respondieran por sus delitos al fugarse a zonas con poca presencia estatal ${ }^{30}$. Con este nuevo Tribunal se pretendía superar este inconveniente al asignársele la jurisdicción sobre las provincias de Panamá y Veraguas, mientras el del Magdalena impartía justicia sobre las restantes provincias. No obstante, como se deduce de una representación que la Cámara Provincial de Santa Marta envió al Congreso de la República en 1846, las quejas persistieron. En la citada representación, justificando la necesidad de establecer un Tribunal con las provincias de Santa Marta y Riohacha, expresaron lo siguiente:

El distrito del Magdalena es demasiado extenso, abraza provincias y lugares entres si muy distantes y, lo que es peor, muy diferentes. Y un solo Tribunal tiene graves dificultades para administrar pronta $\mathrm{y}$ rectamente la justicia en todo él. Al paso que para los litigantes se hacen muy difíciles los reclamos de sus derechos. Muchos de vosotros saben por experiencia cuánto hay de distancia de Riohacha a Cartagena y cuantos obstáculos aumentan aquella distancia ${ }^{31}$.

Las dificultades que enfrentaba el aparato judicial se agudizaban a nivel distrital por la ausencia de la policía y de cárceles seguras. Estas últimas eran, en su mayoría, de palma y bahareques ${ }^{32}$, ocasionando que, por la fuga

\footnotetext{
${ }^{29}$ Mario Aguilera. "Las penas", Credencial Historia, 148, (2016): 1-2.

${ }^{30} \mathrm{BNC}$, "Extracto de la memoria presentada por el gobernador de Cartagena a la Cámara provincial", Gaceta de la Nueva Granada, Bogotá octubre 25 de 1845.

${ }^{31}$ BLAA, "Solicitando la erección de un Tribunal de Justicia", Semanario de Santa Marta, (Santa Marta) 15 de noviembre de 1846 .

${ }^{32}$ BLAA, "Exposición del gobernador a la Cámara provincial de Santa Marta”, Semanario de Santa Marta, (Santa Marta) octubre 5 de 1845 .
} 
frecuente de los condenados, fueran más los reos prófugos que los juzgados ${ }^{33}$. De igual forma, como usualmente no había personas idóneas para ejercer el cargo de juez, se nombraban jueces legos; personas que sin ser abogados ejercían como jueces, teniendo siempre que acudir a la asesoría de abogados ${ }^{34}$. Al igual que otros funcionarios, los jueces legos tampoco recibían salario alguno, propiciando la desatención de las labores administrativas al dedicarse a sus actividades económicas ${ }^{35}$. Refiriéndose a esta realidad, en 1847 el gobernador de Veraguas afirmaba que la mala administración de justicia en la provincia se debía a que "los juzgados de primera instancia han estado servidos por jueces legos" 36 . Esta situación hizo que, en contextos locales, los tinterillos, figuras que venían desde la Colonia, jugaran un papel preponderante a la hora de llenar esa ausencia de personajes con conocimiento en derecho ${ }^{37}$. Luis Striffler, describiendo el distrito de Caimito, señalaba que "sería casi un paraíso si entre sus vecinos no hubiera tres o cuatro que sabían leer y escribir, no muy bien, pero lo suficiente para hacer un infierno de ese paraíso de sencillez [...] los tinterillos de Caimito, que saben leer y escribir, se valen de esa ventaja para explotar a los ignorantes sabaneros" ${ }^{\prime 3}$.

Representaciones como las expresadas por Striffler sobre los tinterillos pueden llevarnos a perder vista el papel importante que jugaban estos personajes como intermediarios entre las instituciones del Estado y la sociedad. Con una población iletrada y con funcionarios que desconocían la legislatura nacional y provincial, los tinterillos eran esenciales en el funcionamiento del régimen republicano en las zonas rurales; zonas donde vivía la mayor parte de la población. Como lo ha demostrado la historiografía latinoamericana, junto al cura y al alcalde, el tinterillo cumplía una labor importante en la marcha de la administración pública a nivel local ${ }^{39}$.

Las impresiones de viajeros como Striffler pueden generar también la impresión de un Estado que se mantenía indiferente frente al funcionamiento del aparato de justicia y que no introducía cambios tendientes a fortalecer este ramo de la administración pública. Lo cierto es que, como se deduce ocurrido con la previamente citada solicitud de crear un Tribunal de Justicia entre las provincias de Santa Marta y Riohacha, las autoridades gubernamentales sí estaban preocupadas porque la ilicitud fuere controlada a través de los medios

\footnotetext{
${ }^{33}$ BLAA, "Reos prófugos. Circuito judicial de Santa Marta, Ciénaga, Plato y Tenerife", Semanario de Santa Marta, (Santa Marta) septiembre 7 y 14; Biblioteca Bartolomé Calvo (en adelante BBC), "Reos prófugos contra quienes existe causa criminal pendiente en los juzgados de esta provincia", Semanario de la Provincia de Cartagena (en adelante SPC), (Cartagena) junio 6 y 13 de 1847; BNC, "Extracto de la memoria presentada por el gobernador de Panamá en 1846", Gaceta de la Nueva Granada, Bogotá febrero 22 de 1846.

${ }^{34}$ Juan Vélez. "El establecimiento local", 113-143.

35 Ley adicional.

${ }^{36}$ BNC, "Extracto que el gobernador de Veraguas presentó a la Cámara de Provincia", Gaceta de la Nueva Granada, Bogotá febrero 14 de 1847.

${ }^{37}$ Juan Vélez. "Abogados, escríbanos, 13-51; Gabriela Tío. "Los historiadores "hacen justicia”: un atajo hacia la sociedad y el poder en la campaña rioplatense en la primera mitad del siglo XIX”, Revista Historia del Derecho 41, (2011): $199-212$. ${ }^{38}$ Luis Striffler. El rio San Jorge, (San Marcos: edición preparada y financiada por Carmelo y Arístides Ojeda, 1958 ), 97.

39 Juan Carlos Vélez. "Abogados, escríbanos", 13-51; Marc Becker. "En busca de tinterillos. Intermediarios en el mundo indígena ecuatoriano durante el siglo XX", Procesos, 37, (2013): 97-124; Margarita Garrido. "La política local en la Nueva Granada, 1750-1810", ACHSC, 15, (1987): 37-56; Poderes intermedios en la frontera. Buenos Aires y los "entrerríos", siglos XVIII-XIX, Mariana Candedo (Compiladora), (La plata, Universidad Nacional de La plata, 2013): 176.
} 
legales. En efecto, la solicitud mencionada fue aprobada por el Congreso en 1846 y un año después ya estaba en funcionamiento el Tribunal, el cual ejercía jurisdicción sobre las provincias de Santa Marta y Riohacha y estaba integrado por cinco circuitos judiciales: Santa Marta, Riohacha, Valledupar, Chiriguaná y Plato $^{40}$. En 1849, la provincia de Mompox fue adscrita a este Tribunal por su cercanía con la provincia de Santa Marta y lo difícil que le resultaba comunicarse con Cartagena. Con esta decisión, los circuitos judiciales ahora eran Santa Marta, Riohacha, Valledupar, Mompox, Magangué ${ }^{41}$. Poco a poco se iba a configurando un aparato de justicia que, pese a las dificultades que enfrentaba, emitió condenas a través de las cuales nos podemos acercar al tipo de delitos que fueron más frecuentes en el Caribe neogranadino durante la primera mitad del siglo XIX.

\section{Tendencias delictivas en el Caribe en los inicios de la República}

El convencimiento de algunos funcionarios judiciales de impartir justicia para garantizar la tranquilidad de la República, quedó reflejado en las denuncias de los ciudadanos y en las sentencias dictadas por los funcionarios judiciales en la primera mitad del siglo XIX. Aunque se hallan dispersas, organicé 1595 denuncias y sentencias de los Tribunales del Magdalena, Istmo y Santa Marta en algunos años entre 1832 y 1853. Si bien la muestra es pequeña, dado el número de años de estudio, permite señalar algunas conclusiones sobre los delitos cometidos en el Caribe. La primera es que, según el Código Penal de 1837, los casos se distribuyen como aparecen en el cuadro 1.

Cuadro 1: Delitos registrados por los Tribunales Superiores del Magdalena, Istmo y Santa Marta, diversos años, 1832-1853.

\begin{tabular}{|l|l|}
\hline \multicolumn{1}{|c|}{ Categorías } & \multicolumn{1}{c|}{ Delitos } \\
\hline Delitos contra las personas & $\begin{array}{l}\text { Heridas, homicidio, riñas e intento, parricidio, rapto, } \\
\text { seducción, maltrato de obra, sevicia, estupro, } \\
\text { envenenamiento, por fuerza a una mujer (violación), } \\
\text { fratricidio, suicidio, amenazas, fuerza y violencia. }\end{array}$ \\
\hline Delitos contra la propiedad & $\begin{array}{l}\text { Hurto, robos, despojo violento, asalto, incendio, } \\
\text { escalamiento, abigeato, estafa y tentativa, deuda, } \\
\text { ataque y violación de casas. }\end{array}$ \\
\hline $\begin{array}{l}\text { Delitos contra el orden y la } \\
\text { tranquilidad pública }\end{array}$ & $\begin{array}{l}\text { Resistencia a la justicia, fuga de presos, deserción, } \\
\text { soltura de criminales, uso de armas prohibidas, } \\
\text { insubordinación, irrespeto y desobediencia, abandono } \\
\text { de guardia, conspiración, rebelión, sedición, asonada, } \\
\text { inducir a los esclavos a la fuga, resistencia a la } \\
\text { autoridad, ataque armado a la autoridad, maltrato a la } \\
\text { autoridad, varios excesos. }\end{array}$ \\
\hline $\begin{array}{l}\text { Delitos contra la moral } \\
\text { pública }\end{array}$ & $\begin{array}{l}\text { Vagancia, incesto escandaloso, pecado nefando } \\
\text { (sodomía), casamiento clandestino, amancebamiento, } \\
\text { juegos prohibidos, acto carnal público, escándalo, }\end{array}$ \\
\hline
\end{tabular}

\footnotetext{
${ }^{40}$ BNC, "Informe del gobernador de Santa Marta a la Cámara Provincial", Gaceta de la Nueva Granada, Bogotá febrero 27 de 1848.

${ }^{41}$ BNC, "Exposición del gobernador de la provincia de Mompox a la Cámara", Gaceta Oficial, Bogotá noviembre 25 de 1849.
} 


\begin{tabular}{|l|l|}
\hline & $\begin{array}{l}\text { embriaguez, lenocinio, palabras obscenas o } \\
\text { deshonestas. }\end{array}$ \\
\hline $\begin{array}{l}\text { Delitos de los funcionarios } \\
\text { públicos }\end{array}$ & $\begin{array}{l}\text { Mal desempeño, abuso de autoridad, por competencia } \\
\text { de jurisdicción, cohecho. }\end{array}$ \\
\hline $\begin{array}{l}\text { Delitos contra la hacienda } \\
\text { pública }\end{array}$ & Fraude, contrabando, introducir monedas falsas. \\
\hline Delitos contra la fe pública & $\begin{array}{l}\text { Falsificación de documento y firma, perjurio, pérdida } \\
\text { y quema de sumarios, }\end{array}$ \\
\hline $\begin{array}{l}\text { Delitos contra la honra, } \\
\text { fama y tranquilidad } \\
\text { particular }\end{array}$ & Injurias, calumnias, abuso de confianza. \\
\hline Delitos contra la religión & Blasfemia \\
\hline $\begin{array}{l}\text { Delitos contra la salud } \\
\text { pública }\end{array}$ & Intervención de un cadáver. \\
\hline
\end{tabular}

Fuentes: Elaboración propia tomando como refrencias BLAA, Constitucional de Cartagena, (Cartagena) septiembre,10, 20 y 30; octubre 10, 20 y 30; noviembre 10 y 30; diciembre1210,20 y 30 de 1835 ; enero 10,20 y 30 ; febrero 10,20 y 29 ; marzo 19 y 28 ; abril 8 y 18 ; mayo18; junio 8, 18, 28; julio 8; agosto18; septiembre 8; octubre 8 ; noviembre 8 y diciembre 8 de1836; enero 8; marzo 8; abril 18; mayo 8; junio 8; julio 8; agosto 8; septiembre 8 y 28 de 1837; BNC, Gaceta de la Nueva Granada, (Bogotá) agosto 03; octubre 10 y 12; diciembre 7 y 14 de1845; BLAA, El Semanario de Santa Marta, (Santa Marta) marzo 3; 8; abril 28; mayo 18; julio 6; septiembre 7 y 14 de 1845; BNC, Gaceta de la Nueva Granada, (Bogotá) enero 18, marzo 22 de 1846, mayo 3, 31; septiembre 6; BLAA, Semanario de Santa Marta, (Santa Marta) enero 25; febrero 1; 15; marzo 1, 8; abril 26 de 1846; BNC, Gaceta de la Nueva Granada, (Bogotá) abril 8 de 1847; BBC, SPC, Cartagena, agosto 20; septiembre 10 de 1848; BBC, El Fanal, (Cartagena) febrero 1; 8; marzo 1 de 1849, SPC, marzo 3, 17, 31; abril 28; mayo 26; junio 23 ; julio 7,14, 24; agosto 8 de 1850 .

La segunda es el predominio de los delitos contra las personas y la propiedad, representando los primeros el $39,70 \%$ y los segundos el $25,90 \%$ de los casos, como se observa en los cuadros 2 y 3 y en la gráfica 1 . En el cuadro 3 se aprecia que las heridas era el delito más frecuente con 422 casos, $(26,50 \%)$ y los homicidios fueron $114(7,10 \%)$. Los números de ambos delitos contradicen la imagen construida por una parte de la historiografía costeña, la cual describió a la región como tranquila y ajena a los conflictos. Lo que se evidencia es que en el Caribe eran usuales altercados y conflictos en los que se involucraban hombres y mujeres, ricos y pobres, negros y blancos, autoridades estatales y eclesiásticas ${ }^{42}$.

Cuadro 2: Categorías y número de delitos cometidos en las jurisdicciones de los Tribunales Superiores del Magdalena, Istmo y Santa Marta, diversos años, 1832-1853.

\begin{tabular}{|l|r|r|}
\hline \multicolumn{1}{|c|}{ Categorías } & Número de casos & Porcentajes \\
\hline Delitos contra las personas & 634 & 39.70 \\
\hline Delitos contra la propiedad. & 413 & 25.90 \\
\hline Delitos contra el orden y la tranquilidad pública. & 271 & 17.0 \\
\hline Delitos de los funcionarios públicos & 95 & 6.0 \\
\hline Delitos contra la moral pública & 79 & 5.0 \\
\hline Delitos contra la hacienda pública & 43 & 2.70 \\
\hline
\end{tabular}

${ }^{42}$ Gabriel Porras. Cartagena Hispánica, 1533 a 1810, (Bogotá: Biblioteca de Autores Colombianos, 1954), 210; Orlando Fals Borda. Historia Doble de la Costa. Tomo 2. El presidente Nieto, (Bogotá: Universidad Nacional y otros, 2002$), 209$. 


\begin{tabular}{|l|r|r|}
\hline Delitos contra la fe pública & 27 & 1.70 \\
\hline $\begin{array}{l}\text { Delitos contra la honra, fama y tranquilidad } \\
\text { particular }\end{array}$ & 24 & 1.50 \\
\hline Delitos contra la religión & 3 & 0.18 \\
\hline Delitos contra la salud pública & 1 & 0.06 \\
\hline Varios delitos & 5 & 0.30 \\
\hline Total & 1.595 & $100 \%$ \\
\hline
\end{tabular}

Fuentes: Elaboración con base en las fuentes del Cuadro 1.

Las formas de dirimir estos conflictos incluían denuncias por injuria y calumnia, riñas, maltrato de obra, heridas y homicidios y obedecían a varias razones. Para Colmenares: "las tensiones que imponía el abigarramiento en viviendas estrechas o las chispas que saltaban de la fricción en tiendas, en mercados, en ventas y en pulperías, estimuladas casi siempre por la bebida, daba lugar a ofensas frecuentes" ${ }^{43}$. Las riñas entre padres e hijos, esposos y vecinos aumentaban durante los fines de semana y las fiestas religiosas ${ }^{44}$. Por eso, para las autoridades esos días: "dañan a la moral, porque la ociosidad de los días festivos y la concurrencia de las gentes a los poblados, con motivo de la santa misa, es causa de la beodez tan común en la clase inferior del pueblo; de frecuentes disturbios, por los cuales se les reduce a prisión muchos días..." 45 .

\section{Gráfico 1: Distribución porcentual de los delitos cometidos en el Caribe} neogranadino, diversos años, 1832-1853

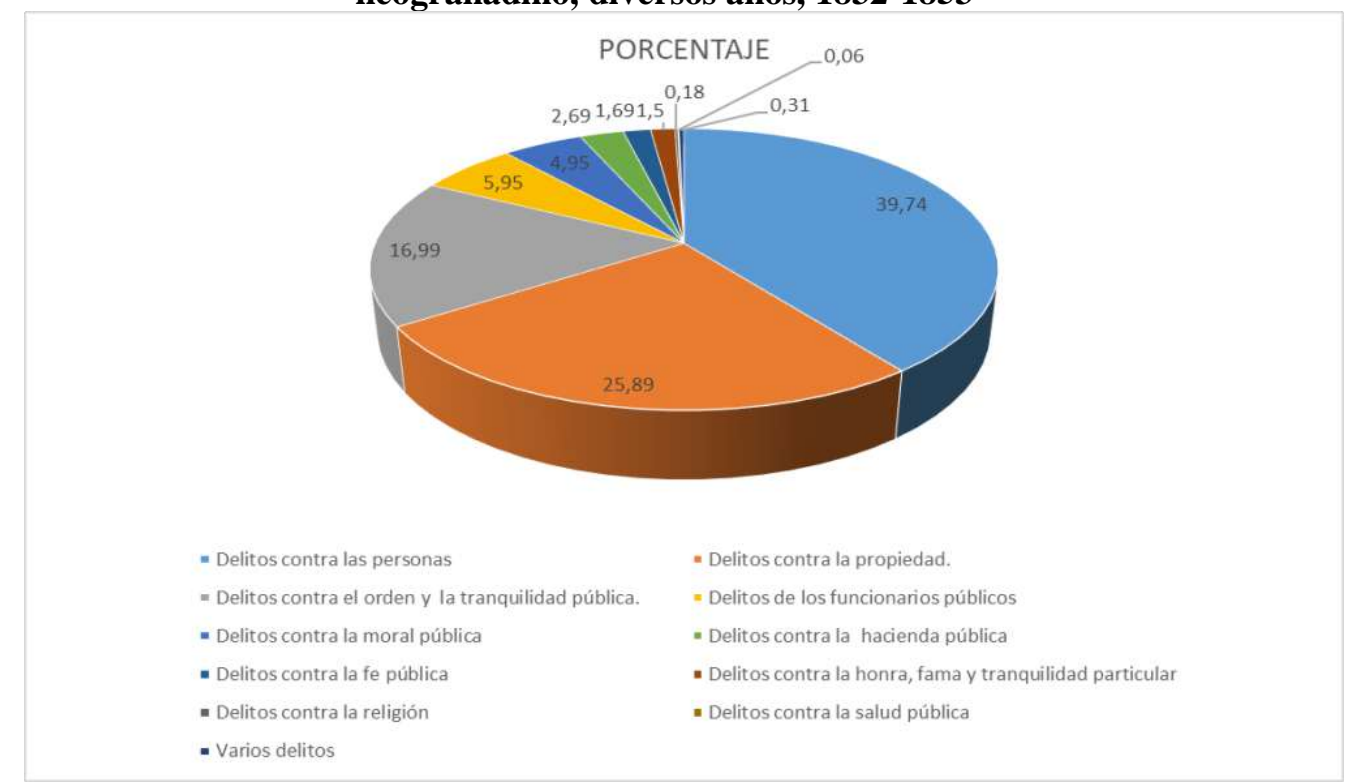

Fuentes: Elaboración propia con base en las fuentes del cuadro 1

Los delitos contra las personas se incrementaban durante las guerras civiles por las rupturas de los clivajes institucionales. Durante la Guerra de los Supremos (1839-1842) aumentaron los homicidios, lo que llevó a decretar la

\footnotetext{
43 Germán Colmenares. El manejo ideológico, 239.

${ }^{44}$ BBC, "Administración de Justica", SPC, (Cartagena) febrero 4 de 1844.

${ }^{45}$ BNC, "Ministerio", Gaceta de Colombia, Bogotá 23 de octubre de 1831.
} 
pena de muerte como escarmiento y no aceptar súplicas de los reos condenados, como se hizo contra Eduardo Velásquez, a pesar de que era menor de edad, porque "en algunos pueblos del Sinú, por desgracia se cometen con frecuencia crímenes atroces como este, y es preciso escarmentar a sus autores, porque la inmoralidad en esta parte es una amenaza a la seguridad de sus habitantes" ${ }^{46}$.

Cuadro 3: Causas criminales recibidas por los Tribunales Superiores del Magdalena, Istmo y Santa Marta según tipo de delito, diversos años, 1832-1853.

\begin{tabular}{|c|c|c|c|}
\hline Delitos & & Delitos & \\
\hline Por heridas & 422 & $\begin{array}{l}\text { Por palabras obscenas } 0 \\
\text { deshonestas }\end{array}$ & 4 \\
\hline Por hurtos, robos y escalamiento & 379 & Por abigeato & 4 \\
\hline Por homicidio & 114 & Por sedición & 4 \\
\hline Por resistencia a la justicia & 86 & Por asonada & 4 \\
\hline Por fuga de presos & 75 & Por perjurio & 4 \\
\hline Por mal desempeño & 58 & Por pecado nefando o sodomía & 3 \\
\hline Por vagancia & 56 & Por blasfemias & 3 \\
\hline Por maltrato de obra y sevicia & 45 & Ataque armado a la autoridad & 3 \\
\hline Por fraude a la hacienda & 26 & $\begin{array}{l}\text { Por la pérdida y quema de } \\
\text { sumarios }\end{array}$ & 3 \\
\hline Por varios excesos & 24 & Por juego prohibidos & 2 \\
\hline Por abuso de autoridad & 24 & Por suicidio & 3 \\
\hline $\begin{array}{l}\text { Por falsificación de documento y } \\
\text { firma }\end{array}$ & 20 & Por escándalos & 2 \\
\hline Por injurias y calumnias & 19 & Por casamiento clandestino & 2 \\
\hline Despojo violento & 18 & Por incesto escandaloso & 2 \\
\hline Por deserción & 17 & Resistencia armada a la policía & 2 \\
\hline Por irrespeto y desobediencia & 15 & Riñas de mujeres & 2 \\
\hline Por uso de arma prohibida & 15 & Lenocinio (Prostitución) & 1 \\
\hline Por rapto y seducción & 15 & Por soltura de un criminal & 1 \\
\hline Por contrabando & 13 & Fuerza y violencia & 1 \\
\hline Por competencia de jurisdicción & 12 & Rebelión & 1 \\
\hline Por insubordinación & 9 & Por la intervención de un cadáver & 1 \\
\hline Por fuerza a una mujer (Violación) & 9 & Por acto carnal público & 1 \\
\hline Por estupro & 9 & $\begin{array}{l}\text { Por ataque a la casa de un } \\
\text { ciudadano }\end{array}$ & 1 \\
\hline Por incendio y conato de incendio & 8 & Por embriaguez repetida & 1 \\
\hline Por conspiración & 8 & Cohecho & 1 \\
\hline Por envenenamiento & 7 & Por maltrato de obra a un militar & 1 \\
\hline Abuso de confianza & 5 & Por asalto & 1 \\
\hline Por amancebamiento & 5 & Provocación a riña & 1 \\
\hline Por varios delitos & 5 & Por tentativa de estafa & 1 \\
\hline Por tentativa de homicidio & 5 & Por deuda & 1 \\
\hline Por abandono de guardia & 5 & Amenazas & 1 \\
\hline \multirow[t]{2}{*}{ Por introducción de moneda falsa } & 4 & $\begin{array}{l}\text { Por inducir a una esclava a la } \\
\text { fuga }\end{array}$ & 1 \\
\hline & & Total & 1595 \\
\hline
\end{tabular}

Fuentes: Elaboración con base en las fuentes del cuadro 1

${ }^{46}$ BBC, “Ejecución de la pena de muerte”, SPC, (Cartagena) diciembre 2 de 1843. 
Los delitos contra las propiedades $(25,90 \%)$ le seguían a los delitos contra las personas. La segunda transgresión más perpetrada en el Caribe era el hurto de menor cuantía. En 1836, este delito era entendido como aquel en que el valor del bien hurtado no excedía de 25 pesos. Sin embargo, no se consideraba como tal cuando consistía en una o más cabezas de ganado mayor, o en cuatro o más de ganado menor, aun cuando el valor de los animales hurtados no excediera de veinte y cinco pesos ${ }^{47}$. Las denuncias muestran que, usualmente, los objetos de hurto eran telas, hilos, cogollos, burros, cerdos y los robos más frecuentes eran ganado y piezas de oro ${ }^{48}$.

El tercer y cuarto lugar en la jerarquía delictiva lo ocupaban los delitos contra el orden y la tranquilidad pública (17\%) y los de los funcionarios públicos (6\%). De la primera categoría, el delito más frecuente era el de resistencia a la justicia. Jueces, alcaldes y comisarios de policías tenían que soportar insultos, reclamos y ataques contras sus personas. En 1847, para el alcalde del distrito de Hibácharo, cantón de Barranquilla, ser empleado parroquial era la posición más penosa para el hombre que quería cumplir con sus deberes, al vivir "amenazado continuamente por el acero cortante de un campesino" 49 . De igual forma, en 1835 José Redondo, comisario de policía del distrito de la Catedral en Cartagena, denunció el desconocimiento de su autoridad por Gervasio Villa, propietario de una tienda en el mencionado barrio. Según Redondo, cuando se dispuso a cobrar el impuesto sobre la tienda, Villa lo ultrajó con palabras soeces y le impidió entrar al establecimiento. Ante estas afrentas, Redondo renunció al cargo para evitar las ofensas jamás recibidas como ciudadano porque "desgraciadamente, algunos individuos no observan el debido respeto ni el tratamiento que debe darse a los agentes del gobierno" 50 .

En el resto de distritos de la provincia de Cartagena la situación era peor porque, como es común en la historia de Colombia, cuanto más se aleja el Estado del centro su poder disminuye. ${ }^{51}$ San Onofre y Tolú eran ejemplo de lo señalado. Refiriéndose al primer distrito, el gobernador de la provincia anotaba en1846 que "hacía algunos años que el distrito parroquial de San Onofre, situado en una montaña localizado del cantón de Lorica, permanecía, no solo sin administración local, sino aun sin autoridades, porque los nombrados para ejercer los destinos parroquiales no se atrevían a posesionarse de su encargo, por temor de los criminales refugiados allí". ${ }^{52}$ Cuatro años más tarde, otro gobernador le escribía al jefe político del cantón de Lorica que tenía conocimiento que en la villa de Tolú y en la parroquia de

\footnotetext{
${ }^{47}$ BLAA, "Ley sobre el modo de proceder contra los vagos y en las causas de hurto de menor cuantía", Constitucional de Cartagena, (Cartagena) mayo 18 de 1836.

${ }^{48}$ BBC, "Sentencia judicial", SPC, (Cartagena) diciembre 17 de 1840; diciembre 18 de 1842; enero 21 de 1843 ; agosto 13 de 1843; marzo 31 de 1844 .

${ }^{49}$ BBC, "Informe al gobernador de la provincia de Barranquilla", SPC, (Cartagena) abril 11 de 1847

${ }^{50}$ BLAA, "Oficio dirigido por el comisario de policía de la Catedral al Jefe político", Constitucional de Cartagena, (Cartagena) noviembre 20 de 1835.

${ }^{51}$ Malcolm Deas, "La presencia de la política nacional en la vida provinciana, pueblerina y rural de Colombia en el primer siglo de la república”, en Del poder y la gramática y otros ensayos sobre historia política y literatura colombianas (Bogotá: Taurus, 2006).

${ }^{52}$ BNC, "Extracto del cuadro que el gobernador de Cartagena presentó a la Cámara de provincia en sus sesiones del año corriente”, Gaceta de la Nueva Granada, Bogotá noviembre 15 de 1846.
} 
San Onofre las leyes no eran acatadas; que se cometían robos y asesinatos impunemente; que la vida y propiedad del ciudadano estaban constantemente amenazadas por una partida de malhechores que existían en sus guaridas o rochelas esperando la ocasión para asaltar al inocente transeúnte. ${ }^{53}$

En parte, esta actitud de la población contra las autoridades obedecía a que la provincia no contaba con un cuerpo de policía organizado, como lo afirmaba en 1852 el gobernador:

Este departamento importante del servicio público no existe en la provincia y aquí [Cartagena] solo existe de él el nombre, siendo imposible haya otra cosa. Cuatro comisarios mal pagados por los fondos comunales, es todo lo que forma el simulacro impropiamente llamado policía, que ni se puede reglamentar ni dirigir. De ahí sucede que es la llamada policía la última que sabe cuándo se ha cometido un crimen...

Los empleados de policía deben ser hombres robustos, de probidad y determinados, por lo mismo que son llamados a comisiones peligrosas; pero con un sueldo miserable, los que general se presentan para servir son hombres enfermizos, sin energía, que solo van a ganar un mal pan para no morirse de hambre... ${ }^{54}$

Este cuadro delictivo lo cierran, en el quinto lugar, los denominados contra la moral pública $(5 \%)$. Llama la atención el número de casos de esta categoría (79) debido a que durante la primera mitad del siglo XIX las campañas contra este tipo de comportamientos se intensificaron en la Nueva Granada ${ }^{55}$. Una de las regiones a la que se asociaba con la vagancia, el concubinato y la beodez fue la Costa. La prensa y las autoridades denunciaban constantemente los "excesos" e "inmoralidad" de sus habitantes. ${ }^{56}$ Verbigracia, en $1836 \mathrm{El}$ Constitucional de Antioquia, cuestionando la ley que establecía que los vagos debían ser destinados al servicio de la marina en la Costa, señalaba que: "si aquella ley se ejecutara cumplidamente en una sola de las provincias de la Costa, en que tanto abundan los ociosos, cierto es que la marina no podría ofrecer servicio para todos". ${ }^{57} \mathrm{Y}$ en 1849 el gobernador de Veraguas afirmaba categóricamente:

El pueblo [...] olvidando el freno de la religión y de las demás sanciones, bajo unos aspectos vive en la relajación más completa [...] porque sin escrúpulo ninguno vive en perpetuo concubinato, en el incesto escandaloso a veces y en la más repugnante lubricidad. Por eso en Veraguas, relativamente a su población, abundan más que en ninguna parte los hijos ilegítimos. ${ }^{58}$

\footnotetext{
${ }^{53}$ BBC, "Seguridad pública", SPC, (Cartagena) marzo 3 de 1850.

${ }^{54}$ BNC, "Informe del gobernador a la Cámara provincial", Gaceta Oficial, Bogotá octubre 11 de 1852.

${ }_{55}^{55}$ Natalia Botero. "El problema de los excluidos, 41-68.

${ }^{56}$ Nancy Appelbaum. La Comisión Corográfica en la Colombia del siglo XIX, (Bogotá: Universidad de los Andes, 2017), 360; Alfonso Múnera. Fronteras imaginadas. La construcción de las razas y de la geografía en el siglo XIX colombiano, (Bogotá: Planeta, 2005), 225.

${ }^{57}$ BLAA, "Vagos", Constitucional de Antioquia, (Medellín) noviembre 1 de 1836.

${ }^{58}$ BNC, "Exposición del gobernador de la provincia de Veraguas a la Cámara", Gaceta Oficial, Bogotá noviembre 4 de 1849.
} 
De manera que la revisión de las sentencias judiciales en el Caribe neogranadino durante la primera mitad del siglo XIX permite visualizar unas tendencias desde la esfera de la ilicitud, marcada por los delitos contra la propiedad y las personas, así como por una recurrente vulneración del orden y la tranquilidad pública y el irrespeto a los funcionarios públicos. Sin embargo, un análisis sobre el contexto económico, político, social y cultural en el cual tuvieron lugar los delitos permite acercarnos a los factores que posiblemente motivaban el desencuentro entre el comportamiento de los individuos y lo establecido en los códigos y leyes.

\title{
4. Clase, raza, género y religión a través del lente de los delitos
}

La variedad de delitos que se cometieron en el Caribe neogranadino revela también las tensiones de clase, raza, género y religión que caracterizaron a este territorio durante la primera mitad del siglo XIX. El hecho de que hurtos y robos ocupen el segundo lugar entre los delitos más cometidos en el Caribe, es un síntoma de la crisis económica que atravesó la región durante la mayor parte del siglo XIX. Además del decrecimiento demográfico y económico, el desmejoramiento de la calidad de vida, la poca oferta laboral y la poca capacidad de ahorros ${ }^{59}$, otro hecho que evidencia la magnitud de la crisis son esas transgresiones, como ha sido estudiado para otros países en los que se ha demostrado que durante las crisis económicas y de hambre se daba un aumento de los delitos contra las propiedades. Hurtos y robos provenían, principalmente, de la miseria y la desesperación; formaban parte de la economía de la escasez y constituían una reacción individual a la falta de alternativas frente a la pobreza y la miseria ${ }^{60}$. Esta situación no pasó desapercibida para la prensa. En 1840, por ejemplo, el periódico El Tiempo anotaba que:

\begin{abstract}
Nuestra situación no puede ser más triste y desesperante la que tenemos ahora en las actuales circunstancias. Después de las calamidades que sufrimos con la epidemia de viruela que se nos ha propagado de un modo aterrador por la indolencia y apatía de nuestros funcionarios públicos (por no decir otra cosa), cuando por todas partes no se oyen más que las voces lastimeras de la viuda, del huérfano, de las madres que desconsoladas lloran la pérdida de los objetos más queridos de su corazón: cuando la agricultura, el comercio, las artes y demás ramos de utilidad común huyen despavoridos de nuestro suelo: cuando el tesoro público está exhausto y no se pagan los gastos mensuales de administración, pues se tiene a la tropa a ración y sin sueldo y a los empleados no se les da aun ni para comer... ${ }^{61}$
\end{abstract}

\footnotetext{
${ }^{59}$ Adolfo Meisel. "La crisis fiscal de Cartagena en la era de la Independencia, 1808-1821", Cuadernos de Historia Económica y Empresarial, 20, 2007: 1-38; Sergio Paolo Solano. "El costo social de la república: los trabajadores de los sistemas defensivos de Cartagena de Indias, 1750-1850”, Historia y Memoria, 18, 2019: 242-287; R. Flórez y S. P. Solano, "Los años de las dificultades", p. 116.

${ }^{60}$ Martín Rheinheimer. Pobres, mendigos, p. 29

${ }^{61}$ BLAA, "Nuestra situación”, El Tiempo, (Cartagena) octubre 11 de 1840.
} 
Nueve años después, este cuadro dantesco era resaltado por el periódico $E l$ Porvenir:

El cólera, esa asoladora epidemia, ha penetrado por todas partes acompañada de la muerte. Las víctimas han sido muchas, unas han bajado a sus tumbas y otras, acaso más desgraciadas, andan errantes por las calles llorando su desamparo. Si, los mendigos y los huérfanos, casi desnudos, sin hogar y con hambre, se les ve de puerta en puerta pidiendo el pan necesario para su subsistencia ${ }^{62}$.

En determinados casos, con el fin de ayudar a sobrellevar la pobreza, personas antes de morir, distribuían su dinero entre los presos pobres, los pobres mendicantes y los pobres vergonzantes. Esta última categoría cobijaba a una franja de los sectores intermedios que, por los cambios políticos y económicos y las epidemias, quedaron en la ruina y ante la vergüenza, la forma como les hacían llegar las limosnas era colocando en el Palacio Municipal de las ciudades una caja de madera con una abertura, y todo aquel que quería ser socorrido introducía, por sí o por intermedio de otra persona, la esquela donde solicitaba la limosna y la calle donde residía. Luego, los curas llevaban el dinero asignado a cada pobre vergonzante ${ }^{63}$.

Las tensiones raciales, propias de una sociedad conformada por blancos, negros, indígenas, mestizos, mulatos, pardos, también salieron a relucir en medio de los delitos y denuncias que cometían y hacían los habitantes. Pese al discurso republicano de la igualdad jurídica de los individuos -representada en la ciudadanía-, en una sociedad que contaba con una larga tradición esclavista y de jerarquías sociales basadas en la raza, las diferencias raciales siguieron utilizándose para generar zozobra y miedo con una posible guerra de razas; marginar social y políticamente e injuriar en público a cualquier ciudadano perteneciente a las castas. Con ello se buscaba cerrar los espacios de participación política, representados en el derecho al voto y en el ejercicio de cargos públicos, que habían alcanzado muchos mulatos, zambos y pardos. Para restarle legitimidad a la autoridad de un funcionario de color, el mecanismo utilizado por los blancos era el insulto racial. Estos elementos permiten validar la existencia de una tensión racial en el Caribe ${ }^{64}$.

La prensa de la época es prolija en el cubrimiento de este tipo de acusaciones y "sublevaciones". En 1834, José Hilario López le informaba al presidente Santander que el gobernador de la provincia de Cartagena, Ignacio de Luque, en una fiesta "insultó a varios presentes y a Vicente Díaz le dijo que era un chismoso, zambo, que se fuera de su casa". ${ }^{65}$ Ese mismo año, un remitido denunciaba a Diego Castro por negarse a ejercer cargos públicos en Barranquilla, lo que terminó enfrentándolo con sus vecinos, los que se

\footnotetext{
${ }^{62}$ BBC, “Una excitación”, El Porvenir, (Cartagena) agosto 8 de 1849.

${ }^{63}$ BBC, "Limosnas”, SPC, (Cartagena) marzo 26 de 1843.

${ }^{64}$ Jorge Conde. Buscando la Nación. Ciudadanía, clase y tensión racial en el Caribe colombiano, 1821-1855, (Medellín: La Carreta, 2009), 370.

65 Jorge Conde. Buscando la Nación, p. 139
} 
referían a él como macaco, monicongo y enano ${ }^{66}$. En junio de1844, el periódico El Samario informaba que la noche del 5 de junio hubo una gran alarma en Santa Marta porque se corrió la noticia de que en la hacienda de Papares "se habían sublevado los negros acaudillados por Labarcés". A las diez de la noche, todo estaba tranquilo al descubrirse que no era cierto y lo que se buscaba era "[...] perder a algún infeliz complicándolo en desórdenes forjados, pues esta es práctica corriente en el día" ${ }^{67}$. Dos meses después, el alcalde de Arroyo Grande denunció al cura por irrespeto e injuria al acusarlo de hurto de ganado y llegar "al extremo de llamarme zambo (como si él fuera blanco) sin camisa y amenazándome con una cadena, descendiendo hasta en las injurias que en cualquiera boca son indignas, mucho más en la de un eclesiástico"68.

La sociedad caribeña de la primera mitad del siglo XIX, juzgada a partir de los delitos, abre la posibilidad de comprender los roles de hombres y mujeres representados en el género. Se esperaba de las mujeres obediencia y sumisión a padres y esposos ${ }^{69}$. Estos roles, sumados a la pobreza y miseria en la que vivían la mayoría de las familias, propiciaban peleas y violencias entre hombres y mujeres, las cuales acababan, muchas veces, en heridas y homicidios. Pero otras formas de violencias contra las mujeres eran el rapto, el maltrato de obra, la sevicia, el estupro, la violación (por fuerza a una mujer ${ }^{70}$. Ejemplo de ello es lo sucedido en Panamá en 1844, cuando Vicente Díaz asesinó a Dolores Lozano y a Salomé Cupri en una tienda porque Dolores no accedió a tener una relación adúltera con él. Según la denuncia, Díaz "amenazó matar a la Lozano...para obligarla a cometer un delito, el cual era el adulterio que debía ser consiguiente a las relaciones que Díaz quería establecer con la infeliz Lozano"71.

Asimismo, las denuncias y condenas de esta categoría nos permiten observar que los mecanismos de resistencia utilizados por las mujeres incluían el uso de acciones legales (representadas en denuncias por maltrato de obra y sevicia, estupro, violación) y acciones de hecho como el envenenamiento de sus parejas. De los 7 casos de envenenamiento, 4 fueron de mujeres contra sus maridos.

Algunos pleitos entre vecinos terminaban en homicidios, como sucedió en Corozal en 1838, cuando Eduardo Velásquez asesinó a Juana Ortúa porque "la desgraciada Ortúa habló mal de su madre"72. En Mompox, en 1841, el esclavo José Covillas, por orden de su amo Tomás Medina, asesinó “a un hombre bajetoncito, claro, vestido de blanco y oriundo de las provincias del

\footnotetext{
${ }^{66}$ BLAA, "Remitido”, El Cartagenero, (Cartagena) junio 25 de 1834.

${ }^{67}$ BLAA, "Sublevación", El Samario, (Santa Marta) junio 14 de 1844.

${ }^{68}$ BBC, "Vindicación”, SPC, (Cartagena) agosto 25 de 1844.

${ }^{69}$ Gloria Bonilla. Las mujeres en la prensa de Cartagena de Indias, 1900-1930, (Cartagena: Universidad de Cartagena,

2011), 319; Mariela Fargas. "La práctica de la justicia en el orden doméstico. El padre de familia en Domingo de Soto y

su tiempo", Studia Histórica, 40,2, (2018): 271-304.

${ }^{70}$ BBC, "Administración de Justicia”, SPC, (Cartagena) enero 22 de 1843.

${ }^{71}$ BBC, "señor Editor del Semanario", SPC, (Cartagena) septiembre 6 de 1844.

${ }^{72} \mathrm{BBC}$, "Ejecución de la pena de muerte", $S P C$, (Cartagena) diciembre 2 de 1843.
} 
interior". El crimen fue llevado a cabo en una canoa en el rio Magdalena, donde Covillas mandó al hombre, a quien tenía amarrado, a que rezara lo que supiera e inclinara "el pescuezo a la borda del buque y con el machete que llevaba por sí solo (Covillas) con sus propias manos descargó tres golpes sobre la cerviz de aquel desgraciado, con los cuales dividió la cabeza de su cuerpo". Medina ordenó el asesinato "para que respondiese por las injurias personales que dizque le había irrogado". ${ }^{73}$

Ciertos homicidios eran cometidos por esclavos, domésticos y concertados por discusiones y evitar castigos de sus amos, capitanes o apoderados. También por rupturas sentimentales entre parejas ${ }^{74}$. Sin embargo, los casos que más impactaban a la sociedad costeña eran los parricidios ${ }^{75}$.

Por su parte, el bajo juzgamiento de los delitos contra la moralidad pública en el Caribe neogranadino, pese a los constantes señalamientos que se hacía en la prensa sobre los mismos, encuentra explicación en el alcance de las normativas nacionales. Aunque el Código Penal era de carácter nacional, al parecer fue ajustado a las realidades regionales y locales ${ }^{76}$. En este caso, factores económicos y culturales sumados a la poca presencia de la iglesia católica en la región influyeron en la disposición de no denunciar y condenar los delitos contra la moral pública. En el caso de la Iglesia Católica, su debilidad se manifestaba en la inexistencia de templos y de curas en muchos distritos. Aline Helg señala que las diócesis de Cartagena y de Santa Marta permanecieron sin obispos hasta 1828. En esta última provincia, en 1833 el número de parroquias había descendido de 72 y antes del final de la guerra, hasta 65. Había un total de 57 clérigos, contando canónigos y sacristanes, cuando se necesitaban $88^{77}$. Como lo dije anteriormente, la carencia de curas en muchos distritos llevó en 1836 a la Cámara provincial de Cartagena solicitar al Congreso extender las excepciones concedidas a Casanare y Pasto, entre las cuales se contemplaba ordenar a los curas sin el grado de teología o los cursos para aprobarlo porque en la provincia un solo cura atendía a dos o a tres iglesias y en su ausencia no había quien lo reemplazara ${ }^{78}$.

Por su parte, ciudadanos y autoridades no desconocían la situación de pobreza de la región. Condenar a una persona por vagancia implicaba pasar por alto la ruina económica, el desmejoramiento de la calidad de vida de muchas familias y las pocas oportunidades laborales. Además, para las autoridades era evidente que nadie estaba exento de caer en la pobreza en una región donde las catástrofes eran moneda corriente. Incendios, inundaciones,

\footnotetext{
${ }^{73}$ BBC, "Administración de justicia. Sentencia de segunda instancia contra José Covilla por asesinato", SPC, (Cartagena) abril 6 de 1843 .

${ }^{74}$ BBC, "Sentencias por homicidio", "Administración de justicia”, "Remitidos", SPC, (Cartagena) enero 22 de 1843 , junio 9 y julio 14 de 1844 .

75 BBC, "Parricidio", SPC, (Cartagena) marzo 31 de 1850.

${ }^{76}$ Giovanni Levi. "Un problema de escala", Relaciones. Estudios de Historia y Sociedad. Vol. 24, No 95, (2003): 287.

${ }_{77}$ Aline Helg. Libertad e igualdad en el Caribe colombiano, 1770-1835, (Medellín: Eafit, 2010), p. 319; Marta Herrera Ángel. Ordenar para controlar. Ordenamiento espacial y control político en las llanuras del Caribe y en los Andes Centrales Neogranadinos. Siglos XVIII, (Medellín: La Carreta Editores/ Ceso/Uniandes, 2007), 364.

${ }^{78}$ BLAA, "Petición de la Cámara provincial”, Constitucional de Cartagena, (Cartagena) enero 20 de 1836.
} 
epidemias, una mala cosecha, terremotos, podían dejar a las personas en la pobreza y la miseria ${ }^{79}$. En 1835, el jefe político del Cantón de Cartagena le informaba al Concejo Municipal que la vagancia y la beodez habían establecido su residencia en Cartagena, muy seguros de no ser perseguidos. Las calles se veían plagadas de hombres sin destino, que eran perseguidos por todos los medios, pero nada se podía hacer porque "la compasión efímera reina en esta ciudad" 80 .

Por otro lado, para ciertos sectores sociales algunos de los delitos contra la moral pública eran formas de vida. De hecho, en Santa Marta y Cartagena el concubinato se extendió después de la Independencia, como consecuencia de la crisis de la Iglesia Católica en la región y se reflejó en la caída del número de matrimonios durante las primeras décadas del siglo XIX; en el comportamiento de algunas mujeres de la elite republicana que arriesgaron su honor de vivir en concubinato con héroes, exponiéndose a sanciones sociales y en el fenómeno de los hijos fuera del matrimonio en las personas de la elite, lo cual habría sido menos tolerado en la sociedad colonial. ${ }^{81}$

A estos comportamientos no escapaban curas y funcionarios públicos. Ejemplo de ello es el cura José María Berástegui, dueño de una hacienda ganadera al sur de Sincelejo y quien tenía cinco hijos con María Josefa Burgos. ${ }^{82}$ Esta tolerancia frente al concubinato fue la que encontró el viajero Isaac Holton en el distrito de El Banco, donde un cura joven tenía doce hijos reconocidos. Para Holton este comportamiento, considerado en otros países y regiones como algo repugnante y escandaloso, tenía una explicación: en la Costa esta conducta no se consideraba un crimen vergonzoso en un hombre soltero, fuera sacerdote o laico. Además, la posición de la mujer no estaba limitada por las estrictas leyes de decoro que los regían a ellos. Su caída no ocasionaba la deshonra permanente ni la exclusión total de la sociedad. Por tanto, encontrar un cura casto en esta región era un fenómeno raro ${ }^{83}$.

En una región donde el comportamiento de una persona no era ajeno a los vecinos, pues se compartían callejones, patios y solares y la mejor referencia de esto la constituía la expresión "público y notorio", ${ }^{84}$ los concubinatos no pasaban desapercibidos para nadie. En ese sentido, las citas y los cuadros permiten sugerir que, al ser algunos de los delitos contra la moral pública prácticas culturales de las que participaban muchos sectores sociales, los caribeños asumieron que estos comportamientos hacían parte del fuero

\footnotetext{
${ }^{79}$ BNC, "Incendio en Lorica", "Incendio en Simití", Gaceta de la Nueva Granada, Bogotá julio 21 de 1833 y mayo 24 de 1846.

${ }^{80}$ BLAA, "Exposición del jefe político al Concejo Municipal", Constitucional de Cartagena, (Cartagena) diciembre 30 de 1835.

${ }^{81}$ María Teresa Ripoll. La elite en Cartagena y su tránsito a la república. Revolución política sin renovación social, (Bogotá: Universidad de los Andes, 2006), 174 y Steinar Saether. Identidades e independencia en Santa Marta y Riohacha, 1750-1850, (Bogotá: Instituto Colombiano de Antropología e Historia, 2005), 300.

${ }^{82}$ Aline Helg. Libertad e igualdad, p. 315.

${ }^{83}$ Aníbal Noguera Mendoza. Crónica grande del Rio de la Magdalena. (Bogotá: Banco Cafetero, 1980), pp. 65-66.

${ }^{84}$ Roicer Flórez y Sergio Paolo Solano. "Liberalismo, ciudadanía y vecindad en la Nueva Granada (Colombia) durante la primera mitad del siglo XIX”, Infancia de la Nación. Colombia en el primer siglo de la República, (Cartagena: Pluma de Mompox, 2011): 69-94.
} 
interno de las personas y no pertenecían al ámbito de lo público. Pese al repudio de gobernadores, viajeros y de la prensa, la baja frecuencia de las denuncias y las condenas muestra que, al parecer, estos comportamientos habían dejado de ser tabúes y no generaban temores en buena parte de su población ${ }^{85}$. Para muchos, la tradición era ley.

\section{Conclusiones}

El estudio de los delitos que con mayor frecuencia se cometieron en el Caribe neogranadino entre 1832 y 1853 revela la necesidad de pensar el funcionamiento del aparato judicial a la luz de un Estado en formación. La tendencia a visualizar tal funcionamiento a partir de las hipótesis que remarcan una ausencia de Estado en la primera mitad del siglo XIX dificulta la comprensión del proceso de configuración de las instituciones que se encargaron de impartir justicia en los inicios de la República neogranadina. Igualmente, quienes privilegian la visión de un Estado que se construye únicamente desde arriba, dejan poco espacio para analizar las formas en que actores regionales y locales contribuyeron al proceso de expansión de las instituciones judiciales.

Este artículo, en vez de insistir en la poco operativa tesis del fracaso de las instituciones judiciales a comienzos de la República, llama la atención sobre la necesidad de interconectar la tradicional visión del Estado desde arriba con su funcionamiento y construcción desde abajo. Al hacerlo, al tiempo que se historiza el diseño institucional que se pensaba desde el Estado Central, emergen las voces de los funcionarios provinciales, distritales y cantonales que, a partir de su ejercicio en el terreno, elevan peticiones y sugieren cambios para mejorar el funcionamiento del poder judicial. La circulación de prensa, característica distintiva de la República, aparece como un actor clave del aparato de justicia. Los funcionarios judiciales, a través de los periódicos, publicaban edictos y sentencias judiciales, mientras que los ciudadanos podían acudir a la misma para informarse de los delitos y resultados de los procesos. Incluso, la desprestigiada imagen de actores informales como los tinterillos, retratados casi siempre como figuras que se aprovechan de masas iletradas, aparecen en su rol de intermediarios entre las instituciones judiciales y sectores sociales que los buscaban en calidad de asesores judiciales.

Este lente interpretativo, antes que ver las leyes establecidas en los códigos como letra muerta y las instituciones judiciales como figuras de papel, las ubica en una dimensión socio-histórica. Esta última dimensión, al tiempo que posibilita ver las tendencias delictivas que marcaron la realidad del Caribe neogranadino durante el período en estudio, abre un marco de análisis para comprender las dinámicas políticas, económicas o sociales en las que estaban inmersos los sectores sociales que contravenían las normas y leyes

${ }^{85}$ Germán Colmenares. El manejo ideológico, p. 234. 
establecidas. Así, por ejemplo, los delitos contra la propiedad, entre ellos los hurtos y los robos, nos hablan de una sociedad marcada por la crisis económica y en la que la poca oferta laboral y capacidad de ahorros hacen parte de la cotidianidad de los individuos. Los términos en los que se hacían las injurias o se cuestionaba la idoneidad de individuos negros o mulatos, revelan las tensiones socio-raciales de sociedades en las que el orden republicano convivía con el régimen esclavista y sus sombras, al tiempo que las disputas entre las parejas ilustran los jerárquicos roles de género y las violencias simbólicas y físicas a las que se enfrentaban las mujeres.

\section{Bibliografía:}

\section{Fuentes primarias:}

Biblioteca Luis Ángel Arango (BLAA), Bogotá, Colombia:

Constitucional de Antioquia, Medellín, Colombia, 1836.

Constitucional de Cartagena, Cartagena, Colombia, 1835, 1836.

El Cartagenero, Cartagena, Colombia, 1834.

El Momposino, Mompox, Colombia, 1846.

El Porvenir, Cartagena, Colombia, 1849.

El Samario, Santa Marta, Colombia, 1844

El Termómetro Político de la Costa, Cartagena, Colombia, 1834.

El Tiempo, Cartagena, Colombia, 1840.

Gaceta de Colombia, Bogotá, Colombia, 1831.

Gaceta de la Nueva Granada, Bogotá, Colombia, 1833, 185,1837, 1838, 1845, 1846, 1847.

Gaceta Oficial, Bogotá, Colombia, 1849, 1851,1852.

Gaceta Oficial de la Nueva Granada, Bogotá, Colombia, 1852.

Semanario de la Provincia de Cartagena (SPC), Cartagena, Colombia, 1840, 1842, 1843, 1844, 1846, 1847, 1848, 1849, 1850.

Semanario de Santa Marta, Santa Marta, Colombia, 1845,1846.

Noguera, Aníbal. Crónica grande del Rio de la Magdalena. Bogotá: Banco Cafetero, 1980. 


\section{Fuentes secundarias:}

Aguilera, Mario. "La administración de justicia en el siglo XIX. Pervivencias del sistema español, adaptación de códigos foráneos, penas y castigos". Credencial Historia, 138, (2001): 8-11.

Aguilera, Mario. “Las penas”. Credencial Historia, 148, (2016): 1-2.

Appelbaum, Nancy. La Comisión Corográfica en la Colombia del siglo XIX, Bogotá: Universidad de los Andes, 2017.

Araya, Alejandra. "Guerra, intolerancia a la ociosidad y resistencia: los discursos ocultos tras la vagancia, Ciudad de México, 1821-1860". Boletín Americanista $\mathrm{N}^{\circ}$ 52 (2002): 23-55.

Argouse, Aude y Sonkajarvi, Hanna. "El papel de los procesos judiciales y administrativos en las prácticas de justicia (siglos XVII-XX), Revista Historia y Justicia $\mathrm{N}^{\circ}$ 8, (2017): 7-10.

Arrom, Silvia. Para contener al pueblo: el hospicio de pobres de la ciudad de México, 1774-1871, México: Centro de Investigaciones y Estudios Superiores de Antropología Social, 2010.

Barbosa, Francisco. Justicia: rupturas y continuidades. El aparato judicial en el proceso de configuración del Estado-Nación en Colombia, 1821-1853, Bogotá: Universidad Javeriana, 2007.

Barreira, Darío y Gabriela Dalla. "El derecho y la justicia entre la historia y la antropología. Breviario de materiales y recursos seleccionados como introducción al tema”, Prohistoria $\mathrm{N}^{\circ} \mathrm{V}, \mathrm{N}^{\circ}$ 5, (2001): 273-293.

Barreira, Darío. "La historia de la justicia y las otras historias”, en: Historia regional. Enfoques y articulaciones para complejizar una historia nacional, Rodolfo Richard-Jorba y Marta Bonaudo (Coord.), (La Plata, Universidad Nacional 2014), 19-39

Becker, Marc. "En busca de tinterillos. Intermediarios en el mundo indígena ecuatoriano durante el siglo XX", Procesos $\mathrm{N}^{\circ} 37$. Revista ecuatoriana de Historia, (2013): 97-124.

Bilot, Pauline. "Construyendo un esquema de la administración de justicia: fuentes, métodos, resultados, Chile, siglo XIX”, Revista Historia y Justicia $N^{\circ} 1$, (2013): $1-27$.

Bonilla, Gloria. Las mujeres en la prensa de Cartagena de Indias, 1900-1930, Cartagena: Universidad de Cartagena, 2011.

Botero, Natalia. "El problema de los excluidos. Las leyes contra la vagancia en Colombia durante las décadas de 1820 a 1840". ACHSC N 39, (2012): 41-68. 
Brangier, Víctor y Morong, Germán. "Desde la justicia al abordaje historiográfico: los expedientes judiciales-criminales decimonónicos del Archivo Nacional Histórico", Historia Da historiografía N. 21, (2016): pp. 96-113.

Bravo, Ivonne. Comportamientos Ilícitos y mecanismos de control social en el Bolívar Grande, 1886-1905, Bogotá: Ministerio de Cultura, 2002.

Candedo, Mariana (Comp.), Poderes intermedios en la frontera. Buenos Aires y los "entrerríos", siglos XVIII-XIX, La plata: Universidad Nacional, 2013.

Colmenares, Germán. "El manejo ideológico de la ley en un periodo de transición", en: Germán Colmenares. Obras completas. Cali: TM Editores/ Universidad del Valle y otros, 1998, 231-264.

Conde, Jorge. Buscando la Nación. Ciudadanía, clase y tensión racial en el Caribe colombiano, 1821-1855. Medellín: La Carreta, 2009.

Corva, María Angélica. Constituir el gobierno, afianzar la justicia. El poder judicial de la provincia de Buenos Aires, 1853-1881, Rosario: Prohistoria, 2014.

Díaz, Yolanda. "Delitos y delincuentes. Cuba en los finales del siglo XIX e inicios del XX", Pensamiento Americano Vol. 10, N 18, (2017): 32-45.

Domínguez, Camilo, Chaparro, Jeffer y Gómez Carla. "Construcción y deconstrucción territorial del Caribe colombiano durante el siglo XIX", Scripta Nova Vol. X, N²08, (2006): 75-85.

Fals Borda, Orlando. Historia Doble de la Costa. Tomo 2. El presidente Nieto, Bogotá: Universidad Nacional/ Banco de la República/El Áncora Editores, 2002.

Fargas, Mariela. "La práctica de la justicia en el orden doméstico. El padre de familia en Domingo de Soto y su tiempo", Studia Histórica Vol. 40, N 2, (2018): 271 304.

Flórez, Roicer y Solano, Sergio Paolo. "Los años de las dificultades. La caja de ahorros de la provincia de Cartagena, Nueva Granada, 1843-1853". América Latina en la Historia Económica Vol. 21, № 2, (2014):116-144.

Flórez, Roicer, Solano, Sergio Paolo. "Liberalismo, ciudadanía y vecindad en la Nueva Granada (Colombia) durante la primera mitad del siglo XIX", en: Infancia de la Nación. Colombia en el primer siglo de la República. Cartagena: Pluma de Mompox, 2011, pp. 69-94.

Flórez, Roicer y Solano, Sergio Paolo. "La reciente historiografía social sobre el Caribe colombiano: logros, limitaciones y posibilidades", en: 20 años de estudios sobre el Caribe colombiano, editado por: Jaime Bonet y Gerson Pérez Bogotá: Banco de la República, 2020, 39-116.

Galante, Mirian. "La historiografía reciente de la justicia en México, siglo XIX: perspectivas, temas y aportes", Revista Complutense de Historia de América Vol. 37, (2011): 93-115. 
Garrido, Margarita. "La justicia y el orden social en Hispanoamérica, siglos XVIII y XIX”, Historia Crítica N²6, (2008): 10-13.

Helg Aline. Libertad e igualdad en el Caribe colombiano, 1770-1835, Medellín: Eafit, 2010.

Herrera, Marta. Ordenar para controlar. Ordenamiento espacial y control político en las llanuras del Caribe y en los Andes Centrales Neogranadinos. Siglo XVIII, Medellín: La Carreta, 2007.

Jurado, Juan. Vagos, pobres y mendigos. Contribución a la historia social colombiana, 1750-1850, Medellín: La Carreta Editores, 2004.

Levi, Giovanni. "Un problema de escala". Relaciones. Estudios de Historia y Sociedad. Vol. 24, N 95, (2003): 279-288.

López, Georgina. "Justicia y criminalidad en el siglo XIX: nuevos enfoques y perspectivas”, Signos Históricos N² 26, (2011): 8-13.

Marocco, Beatriz. Prostitutas, jugadores, pobres y vagos en los discursos periodísticos. Porto Alegre, siglo XIX. (Tesis doctoral, Universidad Autónoma de Barcelona, 2002).

Meisel, Adolfo. "La crisis fiscal de Cartagena en la era de la Independencia, 18081821”, Cuadernos de Historia Económica y Empresarial N² 20, (2007): 1-38.

Múnera, Alfonso. Fronteras imaginadas. La construcción de las razas y de la geografía en el siglo XIX colombiano, Bogotá: Planeta, 2005.

Múnera, Alfonso y Raúl Román. (eds.) La ciudad en tiempos de epidemia. Cartagena durante el siglo XIX e inicios del XX, Cartagena: Instituto Internacional de Estudios del Caribe, 2016.

Múnera Zea, Leopoldo. "Génesis del Estado colombiano: 1810-1831. El proceso de unificación", en: Fragmentos de lo Público-Político. Colombia, siglo XIX. Leopoldo Múnera Ruiz y Nathaly Rodríguez Sánchez (editores), (Bogotá: Universidad Nacional de Colombia/ La Carreta Editores, 2008), 11-84.

Patiño, Beatriz. Criminalidad, ley penal y estructura social en la provincia de Antioquia, 1750-1820, Bogotá: Universidad del Rosario, 2013.

Pitalúa, Maico. "Pensar la ciudad desde los márgenes: vagos, ociosos y malentretenidos en la provincia de Cartagena a inicios del siglo $\mathrm{XX}^{\text {", en: Cultura, }}$ ciudades y economía en el Caribe: una mirada al litoral. Cartagena, editado por Jorge Elías Caro y Raúl Román. Barranquilla: Asociación Colombiana de Estudios del Caribe, 2016, 60-72.

Porras, Gabriel. Cartagena Hispánica, 1533 a 1810, Bogotá: Biblioteca de Autores Colombianos, 1954. 
Prodi, Paolo. Una historia de la justicia. De la pluralidad de fueros al dualismo moderno entre conciencia y derecho, traducido por Luciano Padilla, Buenos Aires: Katz Editores, 2008.

Puerta, Heriberto. La administración de justicia en el Estado soberano de Bolívar, 1870-1880, Cartagena: Cámara Colombiana del libro, 2011.

Restrepo, Luz. Estructura administrativa de la provincia de Bogotá durante el periodo comprendido entre 1832- 1857. (Trabajo de grado para la Maestría en Derecho Administrativo, Bogotá, Universidad del Rosario, 2009).

Rheinheimer, Martín. Pobres, mendigos y vagabundos. La supervivencia en la necesidad, 1450-1850, traducción de Carlos Martínez Ramírez, Madrid: Siglo XXI Editores, 2009.

Ripoll, María. La elite en Cartagena y su tránsito a la república. Revolución política sin renovación social, Bogotá: Universidad de los Andes, 2006.

Rojas, Beatriz. "El municipio libre". Una utopía perdida en el pasado. Los pueblos de Zacatecas, 1786-1835, México: Instituto Mora, Instituto Cultural de Aguascalientes, Colegio de Bachilleres del Estado de Zacatecas, 2010.

Saether, Steinar. Identidades e independencia en Santa Marta y Riohacha, 17501850, Bogotá: Instituto Colombiano de Antropología e Historia, 2005.

Solano, Sergio Paolo. Puerto, Sociedad y conflictos en el Caribe colombiano, 18501930. Cartagena: Observatorio del Caribe/Ministerio de Cultura/Universidad de Cartagena, 2003.

Solano, Sergio Paolo. "El costo social de la república: los trabajadores de los sistemas defensivos de Cartagena de Indias, 1750-1850". Historia y Memoria, 18, (2019): 243-287.

Striffler, Luis. El rio San Jorge. San Marcos: edición preparada y financiada por Carmelo y Arístides Ojeda, 1958.

Tío, Gabriela. "Los historiadores "hacen justicia": un atajo hacia la sociedad y el poder en la campaña rioplatense en la primera mitad del siglo XIX", Revista Historia del Derecho, 41, (2011): 199-212.

Vélez, Juan. "El establecimiento local de la administración de justicia en Antioquia, 1821-1853. El difícil cumplimiento de una promesa republicana". ACHSC Vol. 40, $\mathrm{N}^{\circ} 1,(2013)$ : 113-143.

Vélez, Juan. "Abogados, escríbanos, rábulas y tinterillos. Conflictos por la práctica del derecho en Antioquia, 1821-1843”. Estudios Políticos, 32, (2008):13-51. 